\title{
Geographic context affects the landscape change and fragmentation caused by wind energy facilities
}

\author{
Jay E Diffendorfer ${ }^{\text {Corresp., } 1}$, Monica A Dorning ${ }^{1}$, Jolene Keen ${ }^{1,2}$, Louisa A Kramer ${ }^{1}$, Robert V Taylor ${ }^{1}$ \\ ${ }^{1}$ Geosciences and Environmental Change Science Center, United States Geological Survey, Lakewood, Colorado, United States \\ 2 American Association of Geographers, Washington, District of Columbia, United States \\ Corresponding Author: Jay E Diffendorfer \\ Email address: jediffendorfer@usgs.gov
}

Wind energy generation affects landscapes as new roads, pads, and transmission lines are constructed. Limiting the landscape change from these facilities likely minimizes impacts to biodiversity and sensitive wildlife species. We examined the effects of wind energy facilities' geographic context on changes in landscape patterns using 3 metrics: portion of undeveloped land, core area index, and connectance index. We digitized 39 wind facilities and the surrounding land cover and measured landscape pattern before and after facility construction using the amount, core area, and connectivity of undeveloped land within $1 \mathrm{~km}$ around newly constructed turbines and roads. New facilities decreased the amount of undeveloped land by $1.8 \%$ while changes in metrics of landscape pattern ranged from 50 to $140 \%$. Statistical models indicated pre-construction development was a key factor explaining the impact of new wind facilities on landscape metrics, with pre-construction road networks, turbine spacing, and topography having smaller influences. As the proportion of developed land around facilities increased, a higher proportion of the facility utilized pre-construction developed land and a lower density of new roads were built, resulting in smaller impacts to undeveloped landscapes. Building of new road networks was also a predictor of landscape fragmentation. Utilizing existing development and carefully placing turbines may provide opportunities to minimize the impacts of new wind energy facilities. 
1 Geographic context affects the landscape change and 2 fragmentation caused by wind energy facilities

3 Jay E. Diffendorfer ${ }^{1}$, Monica A. Dorning ${ }^{1}$, Jolene Keen ${ }^{1,2}$, Louisa A. Kramer ${ }^{1}$, and Robert V.

4 Taylor ${ }^{1}$.

5

$6 \quad{ }^{1}$ United States Geological Survey, Geosciences and Environmental Change Science Center,

7 Denver, CO, USA.

8

${ }^{2}$ Present address. American Association of Geographers, Washington, D.C., USA 10

Corresponding Author:

Jay Diffendorfer, United States Geological Survey, Geosciences and Environmental Change Science Center, Denver Federal Center, Lakewood, CO, 80225. USA.

Email address: jediffendorfer@usgs.gov

\section{Abstract}

Wind energy generation affects landscapes as new roads, pads, and transmission lines are constructed. Limiting the landscape change from these facilities likely minimizes impacts on biodiversity and sensitive wildlife species. We examined the effects of wind energy facilities' geographic context on changes in landscape patterns using 3 metrics: portion of undeveloped land, core area index, and connectance index. We digitized 39 wind facilities and the surrounding land cover and measured landscape pattern before and after facility construction using the amount, core area, and connectivity of undeveloped land within $1 \mathrm{~km}$ around newly constructed turbines and roads. New facilities decreased the amount of undeveloped land by $1.8 \%$ while changes in metrics of landscape pattern ranged from 50 to $140 \%$. Statistical models indicated pre-construction development was a key factor explaining the impact of new wind facilities on landscape metrics, with pre-construction road networks, turbine spacing, and topography having smaller influences. As the proportion of developed land around facilities increased, a higher proportion of the facility utilized pre-construction developed land and a lower density of new roads were built, resulting in smaller impacts to undeveloped landscapes. The building of new road networks was also a predictor of landscape fragmentation. Utilizing existing development and carefully placing turbines may provide opportunities to minimize the impacts of new wind energy facilities.

\section{Introduction}

Generating electricity from wind is a leading technology for meeting energy demand while minimizing greenhouse gas emissions and air pollution. The global installed capacity of wind energy reached 539 GW by the end of 2017 (World Wind Energy Association, 2018) and forecasts suggest continued growth and market penetration doubling to quadrupling levels of 
40 installed onshore wind energy in the next 20 to 30 years (Hand et al., 2012; U.S. Energy

41 Information Administration, 2015; International Energy Agency, 2016). For example, the World

42 Energy Outlook (2016) suggests the installed capacity of wind energy will grow from $6 \%$ of the

$436393 \mathrm{GW}$ (or $384 \mathrm{GW}$ ) of total global energy capacity in 2014 to $13 \%$ of $11,170 \mathrm{GW}(1526 \mathrm{GW}$ ) in

44 2040. While increasing wind energy generation may reduce emissions, it will also result in

45 landscape change associated with developing new facilities, having potentially negative effects

46 on wildlife and other ecosystem functions.

47

48

49

50

51

52

53

54

55

56

57

58

59

60

61

62

63

64

65

66

67

68

69

70

71

72

73

74

75

76

77

78

79

Wind facility footprints can affect wildlife species through changes in the amount, quality, and configuration of habitat, especially through the addition of new roads. The amount of habitat remaining in a landscape can have strong effects on overall species richness and persistence (Rosenzweig, 1995), and the size and location of habitat patches can affect species abundances, behavior, and persistence through edge effects, and other ecological processes (Diffendorfer, Gaines \& Holt, 1999; Gibson et al., 2013). A rich and large literature exists documenting the impacts of roads on ecosystems and their functions, creating a subfield of research called "road ecology" (Forman et al., 2002). Roads affect species directly via habitat loss, roadkill, and behavioral avoidance, as well as indirectly through modifications to the abiotic environment and conveyance of chemicals and noise (Forman \& Alexander, 1998; Coffin, 2007). Wind turbines transform relatively small percentages of the land areas they occupy; however, the roads between turbines add to the total land transformation associated with a facility and cause extensive changes in landscape configuration, fragmenting remaining wildlife habitat. Thus, the road networks associated with facilities are a fundamental mechanism causing changes to terrestrial ecosystems.

A key question is how can new wind facilities be sited and designed to maximize energy production while minimizing potential negative impacts to the environment associated with the facility footprint? A number of countries plan new wind facilities with the goal of minimizing environmental consequences. For example, the European Union has guidelines associated with Natura 2000 that describe a 'strategic planning' approach to wind energy development (European Commission, 2011), and the United States developed voluntary siting guidelines (U.S. Fish and Wildlife Service, 2016) which recommended a tiered evaluation of locations for new facilities. Both of these approaches include considerations of habitat loss and fragmentation caused by the wind facility. Understanding what drives the levels of land transformation, fragmentation, and road network expansion associated with new facilities could inform siting decisions.

Both the roads and the total amount of land transformed by facilities have been estimated and compared across different types of energy (Fthenakis \& Kim, 2009; Evans \& Kiesecker, 2014). Estimates of the land transformation from wind facilities vary by an order of magnitude (Diffendorfer \& Compton, 2014) but we do not know why. We currently have not fully investigated the causes of variation in levels of land transformation (measured as ha/MW of installed capacity) and road network expansion across facilities. The few studies that have investigated this variation suggest the amount of transformation depends on factors intrinsic to 
80 the turbines themselves and on the geographic context in which a facility is sited (Denholm et al.,

81

82

83

84

85

86

87

88

89

90

91

92

93

94

95

96

97

98

99

100

101

102

103

104

105

106

107

108

109

110

111

112

113

114

115

116

117

118

2009; Jones \& Pejchar, 2013; Diffendorfer \& Compton, 2014). Jones and Pejchar (2013) showed individual wind turbines had fewer impacts at locations with more pre-construction development at the scale of $1 \mathrm{~km}$ around each turbine. Diffendorfer and Compton (2014), showed geographic context influenced the total amount of land transformation caused by wind facilities, with facilities on tilled or flat landscapes requiring less land than those in forested locations or on hills and mesas. These studies focused primarily on the drivers of the total land area developed by a facility and did not assess drivers of landscape fragmentation or expansion of road networks. Determining why the levels of land transformation, fragmentation, and roads vary across facilities may allow the siting of wind energy that minimizes levels of landscape change, and perhaps impacts on terrestrial species.

We investigated how new wind facilities affect the loss and fragmentation of undeveloped lands with a focus on the new roads built during construction. In particular, we ask if factors associated with the turbines themselves (size and spacing), topography, and preconstruction land use affect the levels of impact caused by facilities. Based on previous results by Jones \& Pejchar (2013) and Diffendorfer \& Compton (2014) we expected facilities placed in landscapes dominated by human activity to utilize existing road networks, resulting in fewer new roads and a higher proportion of new infrastructure on developed land. Thus, sites with more pre-construction development would have lower amounts of loss and fragmentation of undeveloped lands. We also expected larger turbines would be spaced farther apart, and these greater distances between turbines would require a larger road network. Similarly, facilities with more turbines would require more roads. These factors may or may not affect fragmentation metrics as greater turbine spacing or more turbines would also increase the total extent of a facility, a potential confounding factor for some metrics. Finally, we expected facilities at locations with more topographic relief to require larger road networks, as roads follow topography. We expected these sites to have higher levels of loss and higher fragmentation of undeveloped lands than sites with less topographic relief.

\section{Materials \& Methods}

We selected 39 facilities across the United States, sampling across gradients in topography, turbine capacity, land cover, and turbine string configuration (for facility selection details and a table describing the facilities see Diffendorfer \& Compton (2014)). We did not develop a fully orthogonal study design because some combinations of the stratifying variables did not exist. For example, there were no $3 \mathrm{MW}$ facilities in flat and forested locations. We digitized development associated with each facility as well as pre-construction land cover. We then used an information-theoretic modeling approach to understand how various facility, topographic, and pre-construction characteristics influenced change in landscape fragmentation at each site. 
119 Digitizing procedures. The digitizing process included a number of steps. First, we digitized the 120 surface development, road networks, and turbine locations created during the installation of 121 facilities (Diffendorfer \& Compton, 2014). Second, we delineated the study extent at each 122 facility by buffering the newly constructed hardened surface road network and turbine locations 123 by $1 \mathrm{~km}$ and then merged and dissolved these into a single layer. Third, we manually digitized

124

125

126

127

128

129

130

131

132

133

134

135

136

137

138

139

140

141

142

143

144

145

146

147

148

149

150

151

152

153

154

155

156

157

158 the pre-construction roads and land cover within the study extent for each facility.

We considered the buffer distance for determining the study extent and how it could affect the measured impacts of new facilities. As buffer size increases, so does the area of the study extent, making the relative area impacted by the wind facility smaller. For example, imagine studying a single turbine with 2 ha of development surrounded by undeveloped land. The proportion of the study site occupied by the development changes as the buffer around it increases $(0.23$ at $200 \mathrm{~m}, 0.038$ and $500 \mathrm{~m}$, and 0.009 at $1 \mathrm{~km})$. We selected a $1 \mathrm{~km}$ buffer for three reasons. First, to study the role of geographic context on development, we wanted a spatial scale that was large enough to adequately represent the pre-construction land cover. Second, buffers larger than $1 \mathrm{~km}$ began to create oversized study extents, with wind facilities making up a diminishingly small amount of the land surface. Third, Jones \& Pejchar (2013) used a $1 \mathrm{~km}$ buffer, allowing us to make comparisons between studies using the same spatial scale.

We used high-resolution digital photographs to map both pre-construction and postconstruction roads using on-screen digitizing methods. We started with existing road data (from either national, state, or county sources) and then digitized additional roads based on $1 \mathrm{~m}$ resolution USDA/NRCS Digital Orthophoto Quad Imagery (DOQ) mosaics in ArcMap 10.4 and 10.5 (ESRI, 2014). We selected imagery with the year nearest to the initial operational date of the wind facility for both pre and post construction roads. For example, to digitize preconstruction roads with a facility that began operations in June 2010 and 2007, 2009 and 2011 imagery was available, we used the 2009 imagery immediately prior to June 2010. Similarly, the imagery closest to, yet after, June 2010 was used to digitize post-construction roads. In this case, if 2010, 2012, and 2014 imagery were available, we used 2012 imagery. When DOQs were not available, we used the ESRI "imagery" basemap (which is not dated) available in ArcMap and matched this to Google Earth data imagery to attain a year.

In some instances, we observed other roads in the digital imagery that were not mapped in existing road datasets. We included these when 1) they were wider than $3 \mathrm{~m}$ and 2) vegetation had not grown back in the areas (tracks) that would be driven over by tires. We assumed roads less than $3 \mathrm{~m}$ wide with vegetation regrowth were either not used or used infrequently and would have relatively small impacts compared to larger roads with more traffic. We mapped all preconstruction roads widened during construction but considered these part of the pre-construction conditions.

We required a simplified, consistent land-cover classification across all facilities, despite the broad geographic and ecological range found within the 39 facilities. We reclassified the 20 land-use types in the 2011 National Land Cover Dataset (NLCD) (Homer et al., 2015) into 'undeveloped' and 'developed', and retained the original open water classification. Undeveloped

Peer) reviewing PDF | (2018:12:33453:2:0:NEW 10 May 2019) 
159 lands included NLCD categories of deciduous, evergreen, and mixed forest, shrub/scrub,

160

161

162

163

164

165

166

167

168

169

170

171

172

173

174

175

176

177

178

179

180

181

182

183

184

185

186

187

188

189

190

191

192

193

194

195

196

197

198

grassland/herbaceous, woody, and emergent herbaceous wetlands. Developed lands included NLCD categories of cultivated crops, pasture/hay, developed open space, developed low, medium, and high intensity, and barren land. The remaining NLCD classifications did not overlap with the facility extents. In the NLCD, grassland/herbaceous areas include grasslands supporting grazing, while pasture/hay areas are specifically planted and managed to support livestock and the production of hay crops. In our classification, undeveloped lands represent "natural vegetation", which is potential habitat for species that would utilize a region's natural, undeveloped vegetation types. At Texas wind farms this might represent Blackland prairies or woodlands, while in Pennsylvania, this might represent deciduous forest. Because habitat is species-specific, we did not attempt to link the observed changes in land cover and roads to impacts on species. Given this approach, we considered pasture lands and developed open space as "developed" because they do not represent undeveloped vegetation types. Though these landcover types might support some native species, we assumed they would not likely support species who require undeveloped vegetation types.

The reclassified $30 \mathrm{~m}$ resolution of NLCD data did not accurately match the imagery of developed, undeveloped, and water land-cover types within the $1 \mathrm{~km}$ facility extents. To improve our estimation of pre and post construction land cover, we changed the raster to a $2 \mathrm{~m}$ resolution and manually edited the reclassified NLCD data to more closely conform to high-resolution DOQs using the ARIS grid editor (ARIS, 2017).

Finally, the digitized pre and post construction roads were merged into the land-cover maps by adding roads into the 'developed' classification. The overall approach resulted in pre and post construction $2 \mathrm{~m}$ resolution raster maps of each facility classified as undeveloped, developed, and water within $1 \mathrm{~km}$ extents as well as maps of the pre and post construction road and turbine infrastructure. These GIS files and the data used in the analyses are available at the USGS ScienceBase data catalog (https://doi.org/10.5066/F7639NZB).

Analysis. We used linear models and beta regressions to estimate how the geographic context at a facility, such as topography and levels of pre-construction development, turbine characteristics, and the newly installed roads influenced three landscape metrics measuring aspects of habitat loss and fragmentation (described below). We also used the same approach to estimate how geographic context and turbine characteristics influence new road construction. We initially performed graphical and exploratory analysis of the data, and present paired t-tests describing changes in the number of patches, road length, and the total area of undeveloped land. We also examined correlations between our explanatory variables and used these in model development.

Landscape metrics related to loss and fragmentation. The $(\mathrm{n}=39)$ study sites varied in extent and the amounts of undeveloped land, thus we selected three landscape metrics shown to be independent of the abundance of a land cover type, yet sensitive to levels of aggregation (Wang, Blanchet \& Koper, 2014). These three metrics were the dependent variables in our statistical

Peer) reviewing PDF | (2018:12:33453:2:0:NEW 10 May 2019) 
199

200

201

202

203

204

205

206

207

208

209

210

211

212

213

214

215

216

217

218

219

220

221

222

223

224

225

226

227

228

229

230

231

232

233

234

235

236

237

238

models. The first metric, the change before versus after construction, in the proportion of undeveloped land (area of undeveloped land/total extent) measured the amount of potential habitat affected by the facility. Second, the change in the core area index (CAI) of undeveloped land, assesses the core area of remaining patches as a percentage of the total area of undeveloped land using an area-weighted mean (McGarigal, Cushman \& Ene, 2012). CAI required an edge depth for determining how far into a patch edge effects attenuate. Because species vary in their edge responses, we analyzed 50m, 100m, and 200m edge depths, found similar results, and report results for $50 \mathrm{~m}$ edge depth. For the third metric, we modeled change in the connectance index (CI) for undeveloped land. CI is the proportion of the total connections between patches that occur within a threshold set distance (McGarigal, Cushman \& Ene, 2012). For example, in a 4-patch system, 6 possible connections exist between the patches (1-2, 1-3, 1-4, 2-3, 2-4, and 34). If 3 of these were within the specified distance then $\mathrm{CI}=3 / 6=0.50$. Similar to CAI, we analyzed the change in CI at threshold distances of 100, 200, and 300m and found similar results across all three. We report the $100 \mathrm{~m}$ results. Though not included in our models due to dependence on area (Wang, Blanchet \& Koper, 2014), we also describe changes in the number of patches pre versus post construction. All landscape metrics were calculated using FRAGSTATS on the pre and post-construction raster layers. We initialized FRAGSTATS to consider undeveloped land as the classification of interest. As such, patches were defined as groups of undeveloped pixels separated from other groups by developed land.

The selected metrics measured aspects of land cover associated with ecological patterns and dynamics. For example, habitat loss is recognized as a fundamental driver of declines in biodiversity and the abundance of species (Brooks et al., 2002; Cushman, 2006). The size and presence of core areas affect abundance and demography of species requiring a patch size of a minimum area (Burke \& Nol, 1998; Laurance et al., 1998; Helzer \& Jelinski, 1999). Finally, connectivity affects species movement patterns in fragmented landscapes, their spatial ecology, and persistence (Crooks \& Sanjayan, 2006).

Explanatory variables and candidate models. We used an information-theoretic approach to compare models of the effects of geographic context, turbine characteristics, and newly installed roads on the selected landscape metrics (Burnham \& Anderson, 2002). All models included the coefficient of variation (CV) of elevation, mean slope, turbine capacity, turbine count, mean nearest neighbor distance between turbines (in $\mathrm{m}$ ), proportion of disturbed land pre-installation (area of developed land before construction/area total extent), density of roads pre-installation (length of pre-construction roads/area total extent, $\mathrm{m} / \mathrm{ha}$ ), and the density of new roads (length of new roads/area total extent, $\mathrm{m} / \mathrm{ha}$ ). Thus, the models included variables describing topography, turbine characteristics, levels of pre-existing development and roads, and new roads added during construction. The coefficient of variation $(\mathrm{CV})$ in elevation $(\mathrm{m})$ and the mean slope (degrees) were calculated across all cells within the facility extent.

To avoid multicollinearity, we excluded models with mean nearest neighbor distance and either the number of turbines or the mean turbine size from the candidate model set, while

Peer) reviewing PDF | (2018:12:33453:2:0:NEW 10 May 2019) 
239

240

241

242

243

244

245

246

247

248

249

250

251

252

253

254

255

256

257

258

259

260

261

262

263

264

265

266

267

268

269

270

271

272

273

274

275

276

277

278

retaining all other combinations of these variables. The mean nearest neighbor distance between turbines (m) was correlated (see results) with both the number of turbines at a site and the mean size of turbines (nameplate capacity in MW).

The statistical models included all additive combinations of these variables across the 39 study sites, excluding models with both nearest neighbor distance and turbine size, or nearest neighbor distance and the turbine count. Because our sample size of 39 was small relative to the number of explanatory variables, we limited the candidate model set to models with no more than three explanatory variables but ran models using all possible combinations of 3 explanatory variables.

We also investigated if the density of new roads added during construction was influenced by the explanatory variables related to topography, turbine characteristics, and levels of pre-installation development. These analyses followed the same methods as those described above.

Model implementation. We fit candidate models in R (R Development Core Team, 2013) using either linear models (LMs) or beta regression (using the betareg package when variables ranged from 0 to 1), and performed model selection with MuMin package (R Development Core Team, 2013). Dependent variables analyzed with beta regression included the proportion of undeveloped land and the proportional change in connectance index. These dependent variables were transformed using $y \times(((n-1)+0.5) / n)$ where $\mathrm{n}$ is the sample size (39) and $\mathrm{y}$ is the dependent variable (Smithson \& Verkuilen, 2006). We ranked models using the sample size adjusted AIC (AICc) (Burnham and Anderson, 2002) and model-averaged using AICc weights, which are the log likelihood of the model divided by the sum of the log likelihood across all models. AICc weights are interpreted as the conditional probability that a model is the best model in the candidate model set. We used $\mathrm{R}^{2}$ as an estimate of overall model fit. For the top two ranking models within each candidate model set, we estimated variance inflation factors (VIF's) for each explanatory variable and found none suggesting severe multicollinearity issues in any of the models (highest VIF across all models was 1.91).

To understand what predictor variables were the most important across the candidate model set we followed recent recommendations and used model-averaged standardized coefficients and their standard errors (Cade, 2015; Galipaud, Gillingham \& DechaumeMoncharmont, 2017) and the relative variable importance (Giam \& Olden, 2016). For the modelaveraged standardized coefficients, we model-averaged using all models in the candidate model set, substituting zero in those models when the parameter of interest was absent (Burnham \& Anderson, 2002).

To estimate model coefficients and effect sizes we used the unstandardized modelaveraged estimates, calculated from 'natural' or conditional model averaging, where only those models containing the variable were used. We did this because full model-averaged estimates are used to understand the importance of one variable compared to another but can bias estimates of effect sizes downward (Symonds \& Moussalli, 2011; Grueber C. E. et al., 2011). We used the 
279

280

281

282

283

284

285

286

287

288

289

290

291

292

293

294

295

296

297

298

299

300

301

302

303

304

305

306

307

308

309

310

311

312

313

314

315

316

317

318

unstandardized model-averaged estimates of model coefficients, their standard errors, and biplots of the dependent variables versus the explanatory variable of interest while setting the other variables in the model to their mean values, to understand patterns in the response and to visually check the modeled relationship. For beta regressions, we estimated confidence bands around the fitted lines by bootstrapping the model selection and model averaging process 5000 times then taking the $2.5 \%$ and $97.5 \%$ quantiles.

\section{Results}

Overall patterns. The construction of wind facilities creates relatively narrow, linear development driven by the roads and buried cables between turbines, as well as the access road and electric grid connections to the facility (Supplemental Figures S1). However, the road network and overall patterns of construction vary markedly across facilities (Supplemental Figures S1). In general, these patterns fall within the 'incision' and 'dissection' phases of fragmentation described by (Jaeger, 2000), where a linear feature cuts into or completely bisects a landscape.

Across the 39 sites, turbines with higher capacities were spaced farther apart (turbine capacity vs. mean nearest neighbor distance, $r=0.47, p=0.002$ ). However, sites with more turbines spaced them closer together (turbine count vs. mean nearest neighbor distance, $r=-0.35$, $\mathrm{p}=0.031$ ), yet the turbine count was not correlated with turbine capacity (turbine count vs. turbine capacity, $r=-0.17, p=0.29$ ) or average blade length (turbine count vs. mean average blade length, $\mathrm{r}=-0.08, \mathrm{p}=0.622$ ).

Before construction, the mean length of roads was $44,731 \pm 5199 \mathrm{~m}$ (mean $\pm \mathrm{SE}$ ). The mean length of newly constructed roads was $20,427 \pm 2679$ m or a mean percent increase averaged across facilities of $52.64 \pm 5.9 \%$. The new roads increased the mean number of patches of undeveloped land from $61.31 \pm 9.35$ to $97.18 \pm 10.71$ (paired t-test, $\mathrm{t}=4.633$, $\mathrm{df}=38, \mathrm{p}<$ 0.001 ). However, because some facilities had large increases in the number of patches (e.g. from 28 to 164), the mean percent increase in the number of patches across facilities was $143 \%$. Patch density within the facility extents also increased from $1.75 \pm 0.26$ to $2.75 \pm 0.29$ patches/ha (paired t-test, $\mathrm{t}=5.194, \mathrm{df}=38, \mathrm{p}<0.001$ ).

While roads, number of patches, and patch density increased from $\sim 50$ to $\sim 140 \%$, the change in the total area of undeveloped land affected by construction was $\sim 2 \%$. Pre-construction, sites had an average of 2,355.07 \pm 369.47 ha of undeveloped land, which was reduced to 2294.17 \pm 359.54 ha after construction (paired-test, $\mathrm{t}=5.5847, \mathrm{df}=38, \mathrm{p}<0.001$ ), with a mean percent decrease across facilities of $-1.89 \%$. This new development $(60.92 \pm 10.91$ ha, average for each facility) was $\sim 7 \%$ of the average area of developed land on the sites pre-construction $(872.04 \pm$ 182.17ha).

\section{What drives the levels of land cover change?}

Change in undeveloped lands. We modeled the change in the proportion of undeveloped land before and after construction. Model selection uncertainty was high with 15 models within 5 
319 AICc units (Supplemental Table S1). Pre-construction development, turbine size, the density of

320

321

322

323

324

325

326

327

328

329

330

331

332

333

334

335

336

337

338

339

340

341

342

343

344

345

346

347

348

349

350

351

352

353

354

355

356

357

358

new roads, and pre-construction road density had high relative variable support (Table 1), but the model-averaged standardized parameter values were very low for turbine size, density of new roads, and pre-construction road density. The standardized model-averaged estimates and relative variable importance (Table 1) indicated pre-construction development had far greater support than the other variables. Facilities with higher proportions of development prior to construction had smaller changes in the proportion of undeveloped land after installation (Figure $1)$.

Core Areas. The amount of change in Core Area Index (with a 50m edge depth) after construction was primarily driven by pre-construction levels of development, pre-construction roads, and new roads (Supplementary Table S1). Standardized model-averaged coefficients and the RVI supported the importance of the three variables and suggested pre-construction development had a larger effect size followed by new road density, and then pre-installation road density (Table 1). Unstandardized model averaged coefficients were large relative to their standard errors for these variables except for pre-construction road density, but even in this case, the $95 \%$ confidence interval did not overlap $0(-0.0602 \pm 1.96 * 0.0232=-0.106$ to -0.015$)$. Increases in pre-construction development (Figure 2a), and pre-construction road density (Figure 2b) resulted in smaller changes in CAI. Change in CAI increased as the density of new roads increased (Figure 2c).

Connectivity. The pre versus post-construction change in the connectance index with a $100 \mathrm{~m}$ threshold distance was primarily affected by levels of pre-construction development, new roads, and average slope. In all cases, support for the variables (RVI and standardized model averaged estimates) was relatively high. Furthermore, unstandardized model averaged estimates were large relative to their standard errors so that confidence intervals did not overlap zero for all three variables. The proportional change in $\mathrm{CI}$ approached zero as levels of pre-construction development increased (Figure 3a). As the density of new roads increased, the proportional change in $\mathrm{CI}$ increased but with considerable variation (Figure 3b). For example, at a density of new roads of $7.5 \mathrm{~m} / \mathrm{ha}$, the change in the CI ranged from 0 to $\sim 0.6$. Finally, sites with higher average slopes had smaller levels of change in CI, though this relationship had relatively high levels of uncertainty (Figure 3c). As with the other variables analyzed, pre-construction development had the largest relative effect size on the change in the connectance index, followed by new road density and then average slope (Table 1).

\section{The role of the proportion of pre-construction development}

To better understand the interaction between the development caused by the facility and the levels of pre-construction development, we calculated the proportion of the wind facilities development that intersected pre-construction developed land. The proportion of wind facility developed land in pre-construction developed areas increased nonlinearly as the proportion of 
359

360

361

362

363

364

365

366

367

368

369

370

371

372

373

374

375

376

377

378

379

380

381

382

383

384

385

386

387

388

389

390

391

392

393

394

395

396

397

398

pre-construction development increased (Figure 4, proportion of facility in pre-construction developed lands $=1.93 *$ proportion of developed land pre-construction $-0.88 *$ proportion of developed land pre-construction ${ }^{2}, \mathrm{R}^{2} \mathrm{adj}=0.95$, AICc vs linear model $=-71.41$ vs. -56.34 ).

New roads. The density of new roads installed at facilities ranged from 2.03 to $11.8 \mathrm{~m} / \mathrm{ha}$. Preconstruction development, the number of turbines, the coefficient of variation in elevation, and the distance between turbines had the highest relative variable importance. However, modelaveraged standard errors suggested less support for the coefficient of variation in elevation (Table 1). The density of new roads declined as the proportion of pre-construction development increased (Figure 5a), increased as the number of turbines at a facility increased (Figure 5b), declined as the distance between turbines increased (Figure 5c), and increased as the coefficient of variation in elevation increased (Figure 5d).

\section{Discussion}

Our study had four main findings. First, the amount of pre-construction development plays a key role in determining the overall impacts of a wind facility on undeveloped lands. Second, the amount of undeveloped land that is developed during construction is much lower than the level of habitat fragmentation created. Third, new roads play a key role in the levels of change in landscape metrics associated with habitat fragmentation. Fourth, topography and turbine variables had fewer direct effects on the habitat fragmentation metrics, though they did affect new road density.

The amount of pre-construction development was a key predictor of change in all of the landscape metrics and the addition of new roads. Unlike other explanatory variables, the preconstruction density of developed land was included in a predominance of the best-supported models and had high values based on measures of relative variable importance. Scatter plots also indicated relatively strong relationships between pre-construction development and landscape metrics. This result, while not surprising, is still important to confirm. Across the sites, as preconstruction development increased, the amount of undeveloped land declined, and higher proportions of the wind facility utilized developed instead of undeveloped land (Figure 4), thus reducing the influence of the facility on the loss and fragmentation metrics.

Similar to pre-construction development, the density of newly constructed roads explained variation in the levels of change in the various landscape metrics. While new roads and pre-construction development were correlated, low variance inflation factors in the models for all landscape metrics suggested new roads explained unique variation in the dependent variables. As density of new roads increased at facilities, core areas and connectivity declined, indicating preconstruction patches of undeveloped land were either diminished in size and/or bisected by the new roads.

Across the 39 sites, the proportional change in the area of undeveloped land was much smaller than the proportional change in the number of patches, the CI, and the CAI. Constructing new facilities consumes space, yet the development is essentially long and narrow, spreading out 
399

400

401

402

403

404

405

406

407

408

409

410

411

412

413

414

415

416

417

418

419

420

421

422

423

424

425

426

427

428

429

430

431

432

433

434

435

436

437

across a network that contains a mix of pre-existing and new roads. The relationship between the pre-existing patterns of undeveloped land and the road influenced-pattern of development caused by the facility creates a process by which area loss is small relative to changes in metrics measuring landscape patterns. This suggests studies that only measuring the levels of land transformation caused by wind facilities, and perhaps other forms of energy, may miss potential impacts caused by road effects and habitat fragmentation.

We note our analyses did not include transmission lines and so only represents facilitylevel, "on-site" impacts. Department of Energy scenario analyses suggests a 20\% expansion of the existing electricity transmission network in the US will be needed to accommodate $404 \mathrm{GW}$ of installed wind energy capacity by 2050 (Department of Energy, 2015). Transmission lines bisect areas and generate disturbance during construction and maintenance and new lines can be controversial (Lienert, Suetterlin \& Siegrist, 2015). The effects of transmission lines likely depend on geographic context and vary by species. Above ground transmission lines are a major source of mortality for birds (Loss, Will \& Marra, 2014) yet the area under these lines can also support native bees (Wagner, Ascher \& Bricker, 2014), nesting birds (Chasko \& Gates, 1982; King et al., 2009) and foraging mammals (Takatsuki, 1992).

Siting new facilities. Is it possible to construct facilities that minimize the levels of habitat loss and fragmentation they create? Our results suggest siting facilities in locations with higher levels of pre-construction development and utilizing existing roads may reduce the impacts of the facilities on undeveloped lands. Jones and Pejchar (2013) also found impacts to a variety of indicators declined as both oil/gas and wind energy was sited in locations with more pre-existing disturbance. Facility-level analyses like ours and Jones and Pejchar (2013) add to an empirical basis for larger scale geospatial analyses that examine how much energy can be placed on already disturbed lands (Kiesecker et al., 2011; Fargione et al., 2012; Baruch-Mordo et al., 2019). However, placing energy in already developed areas may be difficult depending on how compatible the energy type is with the land use. Higher levels of pre-construction development occurred because sites were dominated by agricultural land use or rural to semi-rural homes and their associated land cover such as lawns, cleared land, and roads. Wind energy development is often compatible with agriculture and allows energy generation and crop production to coexist on the same landscape. However, not all electricity markets occur near regions dominated by agriculture.

Placing wind energy facilities in semi-rural areas that include a mix of homes and small farms may be more problematic than in agricultural landscapes. These semi-rural areas have higher population densities and thus more individuals may be opposed to wind energy and building a facility may require permission and lease agreements with multiple landowners. In addition, if counties or municipalities regulate road setback distances (to prevent falling blades or towers from blocking roads, hitting homes, etc), higher road and house densities reduce the number of locations where turbines can be placed (Rogers, Slegers \& Costello, 2012). 
438

439

440

441

442

443

444

445

446

447

448

449

450

451

452

453

454

455

456

457

458

459

460

461

462

463

464

465

466

467

468

469

470

471

472

473

474

475

476

477

Our results also indicate other variables, in addition to pre-construction development, might be considered when siting facilities. Lower densities of newly installed roads meant fewer fragmentation impacts. In addition, facilities with more turbines had higher densities of new roads and the density of new roads declined as the distance between turbines increased. This suggests that for a fixed level of overall generation capacity, using fewer but larger turbines, spaced farther apart, may reduce the density of new roads. Roads and buried power lines are necessary at facilities, and turbines are placed to optimize or maximize energy generation. It may be possible to maximize the use of existing roads, and develop optimization approaches to minimize new roads at facilities or the degree of fragmentation they create (Schweitzer et al., 1997; Chung, Bae \& Kim, 2016). Best management practices may also be utilized to minimize road impacts, such as collection basins to reduce sedimentation, and reduced travel speeds to minimize road impacts on wildlife.

Clearly, pre-construction disturbance and new roads can influence the effects of new wind facilities on landscape change and fragmentation. However, topography may have a relatively smaller, but perhaps important effect. Our previous analysis (Diffendorfer \& Compton, 2014) indicated topography influenced the levels of land transformation, with flatter areas having less transformation than sites with hills. Our new analysis used continuous, not categorical, predictor variables and found relatively weak relationships between landscape metrics and both slope and the coefficient of variation in elevation. Both of these relationships could be explored in more detail as our sample had relatively few facilities in areas with steep, or highly variable, topography.

In practice, our results and those from similar studies could be included in GIS-based siting analyses of wind facilities. A number of studies have considered siting wind or other energy types using GIS, multi-criteria decision methods, or custom software to integrate variables related to energy potential, costs of development, and consequences to humans and natural systems (Tegou, Polatidis \& Haralambopoulos, 2010; Siyal et al., 2015; Latinopoulos \& Kechagia, 2015; Watson \& Hudson, 2015; Milt, Gagnolet \& Armsworth, 2016; Sánchez-Lozano, García-Cascales \& Lamata, 2016; Rafiee et al., 2018). To be most effective, a geospatial planning approach incorporating road impacts would require the dynamic calculation of roads and their impacts via scenario analyses and perhaps optimization. Similar approaches have been used to optimize the location of best management practices within watersheds (Wang, 2001), and prioritize the removal of hydrological barriers (dams, road crossings) in streams across the great lake region (Moody et al., 2017).

Habitat loss, fragmentation, and species impacts. At the scale of our analysis, new facilities decreased the amount of undeveloped land by an average of $\sim 1.8 \%$ with a maximum value of $4.7 \%$. Though not settled, some studies suggest habitat loss is the main cause of declines in biodiversity and that habitat fragmentation (independent of habitat area) plays a much smaller role (Yaacobi, Ziv \& Rosenzweig, 2007; Fahrig, 2013) but see (Hanski, 2015). More research is needed to understand if the habitat loss and fragmentation from wind facilities has negative

Peer] reviewing PDF | (2018:12:33453:2:0:NEW 10 May 2019) 
478 consequences on species. However, the relatively small amounts of loss of undeveloped land (at $4791 \mathrm{~km}$ scales), suggests wind energy may be less likely to generate declines in species richness 480 associated with habitat loss, and more likely to impact a set of species uniquely sensitive to the 481 types of development created by the facility.

$482 \quad$ Following the hypothesis, and studies supporting it, that urbanization homogenizes 483 ecological communities (McKinney, 2006; Morelli et al., 2016), facilities located in more

484

485

486

487

488

489

490

491

492

493

494

495

496

497

498

499

500

501

502

503

504

505

506

507

508

509

510

511

512

513

514

515

516

517 developed landscapes may have lessened negative ecological effects not only because they utilize less undeveloped land, but also because the pre-construction levels of development have already extirpated species sensitive to habitat loss and habitat fragmentation. Essentially, this hypothesis suggests pre-construction development has already displaced species the new facility may have displaced. In addition, species capable of existing in developed landscapes may not be negatively impacted by wind energy development (a prediction that has not been tested).

Wind facilities, given the need to place turbines away from each other, do not transform large, continuous tracts of undeveloped land like urban sprawl, agriculture, or forms of energy production that require surface mining. Thus, the impacts from wind energy on species, beyond collision fatalities, may be more likely to involve behavioral avoidance of tall structures, sound, or new human activity at the facility instead of local extirpation caused by habitat loss. In the US, the voluntary wind energy siting guidelines (U.S. Fish and Wildlife Service, 2016) consider 'fragmentation sensitive species' and the need to "Minimize the number and length of access roads; use existing roads when feasible". Our results support this focus.

Other studies on energy and land transformation. Similar to Jones \& Pejchar (2013) we found that the geographic context in which wind energy is developed changes the levels of impact. Using turbines in Colorado and Wyoming, Jones \& Pejchar (2013) found fewer impacts on indicators of biodiversity and ecosystem services at individual turbines with more preconstruction development. We found similar patterns at facilities across the US and in a wide variety of vegetation types. We estimated wind facilities nearly doubled the length of roads (a $100 \%$ increase), while Jones \& Pejchar (2013) estimated an increase of $\sim 250 \%$ ( 450 to $\sim 1600 \mathrm{~m}$ of road, Figure 4 of their paper). Both studies used a $1 \mathrm{~km}$ buffer. It is possible our study had a larger proportion of sites with high levels of pre-construction development and thus estimated lower levels of new roads. However, we digitized entire facilities and therefore included areas that had roads, but no new turbines, within the study extent. Jones \& Pejchar (2013) centered each sampling location at a turbine, and thus always sampled an area that included a turbine and its newly built access road. This difference in sampling entire facilities versus individual turbines likely caused the differences in the predicted changes to roads from wind energy development in our studies.

The negative relationship between levels of pre-construction development and the amount of land change caused by the construction of wind facilities likely holds true for other forms of energy. Jones and Pejchar (2013) found this pattern for oil and gas wells. The strength of this relationship indicates it should be considered in broader scale or generalized analyses of 
518 the land transformation caused by energy (Fthenakis \& Kim, 2009; McDonald et al., 2009;

519 Trainor, McDonald \& Fargione, 2016). For example, Trainor, McDonald \& Fargione (2016) use

520 a single value of 'land use efficiency' $\left(\mathrm{km}^{2} / \mathrm{TWhr}\right)$ to extrapolate the amount of land cover

521 change caused by different energy types across the US under different development scenarios.

522 Across the facilities we digitized, $39.0 \pm 7.0 \%$ (mean \pm SE) of the facility was located in already

523 developed land. If a concern about energy development is the impacts to undeveloped lands, then

524 perhaps we should not include parts of the facility that utilize existing developed land when

525 calculating land use efficiency. Furthermore, extrapolations about future land use effects of

526 energy will improve if they consider where that new energy infrastructure will be located relative

527 to existing development.

528

\section{Conclusions}

530 Our results support the intuitive, but not well-tested, hypothesis that the geographic context in

531

532

533

534

535

536

537

538

539

540

541

542

543

544

545

546

\section{Acknowledgments}

548 Astute feedback from two anonymous reviewers and T. Conkling greatly improved the paper.

549 Roger Compton (USGS, retired) performed the original digitizing of the post-construction

550 facilities and we thank him for his work. Any use of trade, firm, or product names is for

551

552

553

554

which energy is developed can alter the types and levels of impacts such development has on natural systems. In particular, we found levels of pre-construction development and new roads influenced the impacts of wind facilities on undeveloped land, and the expansion of road networks was further influenced by facility design. Our results suggest careful siting and planning of new facilities that optimize energy outputs while utilizing already disturbed locations and minimizing new roads may limit impacts. Based on these conclusions, we also expect that energy suitability analysis and comparisons of energy impacts across sources would benefit from the inclusion of geographic context. Even if one form of energy generates more land transformation per unit of energy produced, one may overlap endangered species and urban areas, while the other may not. These interactions between energy and the locations of other resources affect how we measure impacts and our ability to develop energy resources. Conflicts with other co-located resources and land uses may cause energy developments to violate legal standards, become too costly, or exceed the level of impact society is willing to accept, causing those energy resources to become 'stranded.' These effects could be anticipated and better accounted for by considering geographic context when quantifying energy development impacts. descriptive purposes only and does not imply endorsement by the U.S. Government.

\section{References}

ARIS. 2017. ARIS grid and raster editor for ArcMap. Utrecht, The Netherlands: ARIS. 
555 Baruch-Mordo S, Kiesecker JM, Kennedy CM, Oakleaf JR, Opperman JJ. 2019. From Paris to

556

557

558

559

560

561

562

563

564

565

566

567

568

569

570

571

572

573

574

575

576

577

578

579

practice: sustainable implementation of renewable energy goals. Environmental

Research Letters 14:024013. DOI: 10.1088/1748-9326/aaf6e0.

Brooks TM, Mittermeier RA, Mittermeier CG, Da Fonseca GAB, Rylands AB, Konstant WR, Flick P, Pilgrim J, Oldfield S, Magin G, Hilton-Taylor C. 2002. Habitat loss and extinction in the hotspots of biodiversity. Conservation Biology 16:909-923.

Burke DM, Nol E. 1998. Influence of food abundance, nest-site habitat, and forest fragmentation on breeding Ovenbirds. The Auk 115:96-104.

Burnham KP, Anderson DR. 2002. Model selection and multimodel inference: A practical information-theoretic approach. New York: Springer-Verlag.

Cade BS. 2015. Model averaging and muddled multimodel inferences. Ecology 96:2370-2382.

Chasko GG, Gates JE. 1982. Avian Habitat Suitability along a Transmission-Line Corridor in an Oak-Hickory Forest Region. Wildlife Monographs:3-41.

Chung JH, Bae YK, Kim J. 2016. Optimal sustainable road plans using multi-objective optimization approach. Transport Policy 49:105-113.

Coffin AW. 2007. From roadkill to road ecology: A review of the ecological effects of roads. Journal of Transport Geography 15:396-406.

Crooks K, Sanjayan M. 2006. Connectivity Conservation. New York: Cambridge.

Cushman SA. 2006. Effects of habitat loss and fragmentation on amphibians: A review and prospectus. Biological Conservation 128:231-240.

Denholm P, Hand M, Jackson M, Ong S. 2009. Land-use requirements of modern wind power plants in the United States. NREL/TP-6A2-4 5834. National Renewable Energy Laboratory.

Department of Energy. 2015. Wind Vision: A new era for wind power in the United States. DOE/GO-102015-4557. 
580 Diffendorfer JE, Compton RW. 2014. Land cover and topography affect the land transformation $581 \quad$ caused by wind facilities. PLoS ONE 9:e88914.

582 Diffendorfer JE, Gaines MS, Holt RD. 1999. Patterns and impacts of movements at different 583 scales on small mammals. In: Barrett GW, Peles J eds. The Landscape Ecology of 584 Small Mammals. New York: Springer-Verlag, 63-88.

585 ESRI. 2014. ArcMap: Release 10.1. Redlands, CA: Environmental Systems Research Institute. 586 European Commission. 2011. EU guidance on wind energy development in accordance with the $587 \quad$ EU nature legislation.

588 Evans JS, Kiesecker JM. 2014. Shale gas, wind and water: assessing the potential cumulative 589 impacts of energy development on ecosystem services within the marcellus play. PLoS 590 ONE 9:e89210.

591 Fahrig L. 2013. Rethinking patch size and isolation effects: the habitat amount hypothesis.

592 Journal of biogeography 40:1649-1663.

593 Fargione J, Kiesecker J, Slaats MJ, Olimb S. 2012. Wind and Wildlife in the Northern Great Plains: Identifying Low-Impact Areas for Wind Development. PLoS ONE 7:e41468.

Forman RTT, Alexander LE. 1998. Roads and their major ecological effects. In: Fautin DG ed. 596 Annual Review of Ecology and Systematics. Palo Alto, California: Annual Reviews Inc., 207-231.

Forman RTT, Sperling D, Bissonette JA, Clevenger AP, Cutshall CD, Dale VH, Fahrig L, France 599 RL, Goldman CR, Heanue K, Jones J, Swanson F, Turrentine T, Winter TC. 2002. Road 600 ecology: science and solutions. Washington, DC: Island Press.

601 Fthenakis V, Kim HC. 2009. Land use and electricity generation: A life-cycle analysis.

602 Renewable and Sustainable Energy Reviews 13:1465-1474.

603 Galipaud M, Gillingham M, Dechaume-Moncharmont X-F. 2017. A farewell to the sum of Akaike 604 weights: The benefits of alternative metrics for variable importance estimations in model 

210X.12835.

607 Giam X, Olden JD. 2016. Quantifying variable importance in a multimodel inference framework. $608 \quad$ Methods in Ecology and Evolution 7:388-397.

609 Gibson L, Lynam AJ, Bradshaw CJA, He F, Bickford DP, Woodruff DS, Bumrungsri S, Laurance 610 WF. 2013. Near-complete extinction of native small mammal fauna 25 years after forest 611 fragmentation. Science 341:1508-1510.

612 Grueber C. E., Nakagawa S., Laws R. J., Jamieson I. G. 2011. Multimodel inference in ecology 613 and evolution: challenges and solutions. Journal of Evolutionary Biology 24:699-711. 614 DOI: 10.1111/j.1420-9101.2010.02210.x.

615 Hand MM, Baldwin S, DeMeo E, Reilly JM, Mai T, Arent D, Porro G, Meshek M, Sandor D. 2012. Renewable electricity futures study (entire report). Golden, CO: National Renewable Energy Laboratory.

618 Hanski I. 2015. Habitat fragmentation and species richness. Journal of biogeography 42:989619 993.

Helzer CJ, Jelinski DE. 1999. The relative importance of patch area and perimeter-area ratio to 621 grassland breeding birds. Ecological Applications 9:1448-1458.

622 Homer C, Dewitz J, Yang L, Jin S, Danielson P, Xian G, Coulston J, Herold N, Wickham J, 623 624 625 Megown K. 2015. Completion of the 2011 national land cover database for the conterminous United States - representing a decade of land cover change information. Photogrammetric Engineering \& Remote Sensing 81:345-354.

International Energy Agency. 2016. World energy outlook, 2016. http://www.worldenergyoutlook.org/: International Energy Agency.

628 Jaeger JAG. 2000. Landscape division, splitting index, and effective mesh size: new measures 629 of landscape fragmentation. Landscape Ecology 15:115-130. 
630 Jones NF, Pejchar L. 2013. Comparing the ecological impacts of wind and oil \& gas

631 development: a landscape scale assessment. PLoS ONE 8:e81391.

632 Kiesecker JM, Evans JS, Fargione J, Doherty K, Foresman KR, Kunz TH, Naugle D, Nibbelink 633 NP, Niemuth ND. 2011. Win-Win for Wind and Wildlife: A Vision to Facilitate Sustainable 634 Development. PLOS ONE 6:e17566. DOI: 10.1371/journal.pone.0017566.

635 King DI, Chandler RB, Collins JM, Petersen WR, Lautzenheiser TE. 2009. Effects of width, edge 636 and habitat on the abundance and nesting success of scrub-shrub birds in powerline 637 corridors. Biological Conservation 142:2672-2680. DOI: 10.1016/j.biocon.2009.06.016.

638 Latinopoulos D, Kechagia K. 2015. A GIS-based multi-criteria evaluation for wind farm site 639 selection. A regional scale application in Greece. Renewable Energy 78:550-560. DOI: $640 \quad$ 10.1016/j.renene.2015.01.041.

641 Laurance WF, Ferreira LV, Rankin-de Merona JM, Laurance SG. 1998. Rain forest 642 fragmentation and the dynamics of Amazonian tree communities. Ecology 79:2032-

643 2040.

644 Lienert P, Suetterlin B, Siegrist M. 2015. Public acceptance of the expansion and modification of 645 high-voltage power lines in the context of the energy transition. Energy Policy 87:573-

646 583. DOI: 10.1016/j.enpol.2015.09.023.

647 Loss SR, Will T, Marra PP. 2014. Refining Estimates of Bird Collision and Electrocution 648 Mortality at Power Lines in the United States. PLOS ONE 9:e101565. DOI:

649 10.1371/journal.pone.0101565.

650

McDonald RI, Fargione J, Kiesecker J, Miller WM, Powell J. 2009. Energy sprawl or energy efficiency: climate policy impacts on natural habitat for the United States of America. PLOS ONE 4:e6802.

McGarigal K, Cushman SA, Ene E. 2012. FRAGSTATS v4: spatial pattern analysis program for 654 categorical and continuous maps. Computer software program produced by the authors 
655

656

657

658

659

660

661

662

663

664

665

666

667

668

669

670

671

672

673

674

675

676

677

678

679

at the University of Massachusetts, Amherst. Available at the following web site: http://www.umass.edu/landeco/research/fragstats/fragstats.html.

McKinney ML. 2006. Urbanization as a major cause of biotic homogenization. Biological Conservation 127:247-260.

Milt AW, Gagnolet TD, Armsworth PR. 2016. The costs of avoiding environmental impacts from shale-gas surface infrastructure. Conservation Biology 30:1151-1158. DOI: 10.1111/cobi.12766.

Moody AT, Neeson TM, Wangen S, Dischler J, Diebel MW, Milt A, Herbert M, Khoury M, Yacobson E, Doran PJ, Ferris MC, O’Hanley JR, Mclntyre PB. 2017. Pet Project or Best Project? Online Decision Support Tools for Prioritizing Barrier Removals in the Great Lakes and Beyond. Fisheries 42:57-65. DOI: 10.1080/03632415.2016.1263195.

Morelli F, Benedetti Y, Ibáñez-Álamo JD, Jokimäki J, Mänd R, Tryjanowski P, Møller AP. 2016. Evidence of evolutionary homogenization of bird communities in urban environments across Europe. Global Ecology and Biogeography 25:1284-1293.

R Development Core Team. 2013. R: A language and environment for statistical computing. R foundation for statistical computing, Vienna, Austria. ISBN 3-900051-07-0

Rafiee A, Van der Male P, Dias E, Scholten H. 2018. Interactive 3D geodesign tool for multidisciplinary wind turbine planning. Journal of Environmental Management 205:107124. DOI: 10.1016/j.jenvman.2017.09.042.

Rogers J, Slegers N, Costello M. 2012. A method for defining wind turbine setback standards. Wind Energy 15:289-303.

Rosenzweig ML. 1995. Species diversity in space and time. Cambridge; New York: Cambridge University Press.

Sánchez-Lozano JM, García-Cascales MS, Lamata MT. 2016. GIS-based onshore wind farm site selection using Fuzzy Multi-Criteria Decision Making methods. Evaluating the case 

10.1016/j.apenergy.2016.03.030.

682 Schweitzer F, Ebeling W, Rosé H, Weiss O. 1997. Optimization of road networks using 683 evolutionary strategies. Evolutionary Computation 5:419-438.

684 Siyal SH, Mörtberg U, Mentis D, Welsch M, Babelon I, Howells M. 2015. Wind energy 685 assessment considering geographic and environmental restrictions in Sweden: A GIS686 based approach. Energy 83:447-461. DOI: 10.1016/j.energy.2015.02.044.

687 Smithson M, Verkuilen J. 2006. A better lemon squeezer? Maximum-likelihood regression with 688 beta-distributed dependent variables. Psychological Methods 11:54-71. DOI:

689 10.1037/1082-989X.11.1.54.

690

691

Symonds MRE, Moussalli A. 2011. A brief guide to model selection, multimodel inference and model averaging in behavioural ecology using Akaike's information criterion. Behavioral Ecology and Sociobiology 65:13-21.

Takatsuki S. 1992. A case study on the effects of a transmission-line corridor on Sika deer 694 habitat use at the foothills of Mt Goyo, northern Honshu, Japan. Ecological Research 7:141-146. DOI: 10.1007/BF02348492.

Tegou L-I, Polatidis H, Haralambopoulos DA. 2010. Environmental management framework for 698 wind farm siting: Methodology and case study. Journal of Environmental Management 91:2134-2147. DOI: 10.1016/j.jenvman.2010.05.010.

U.S. Energy Information Administration. 2015. Annual energy outlook 2015 with projections to 702 2040.

U.S. Fish and Wildlife Service. 2016. Bald and Golden Eagles: Population demographics and estimation of sustainable take in the United States, 2016 update. Division of Migratory Bird Management. Washington D.C. 
706 Wagner DL, Ascher JS, Bricker NK. 2014. A Transmission Right-of-Way as Habitat for Wild

707

708

709

710

711

712

713

714

715

716

717

718

719

720

721

\section{2}

723

724

725

726

727

728

729

730

731

732

733

734

735

736

Bees (Hymenoptera: Apoidea: Anthophila) in Connecticut. Annals of the Entomological Society of America 107:1110-1120. DOI: 10.1603/AN14001.

Wang X. 2001. Integrating water-quality management and land-use planning in a watershed context. Journal of Environmental Management 61:25-36.

Wang X, Blanchet FG, Koper N. 2014. Measuring habitat fragmentation: An evaluation of landscape pattern metrics. Methods in Ecology and Evolution 5:634-646.

Watson JJW, Hudson MD. 2015. Regional Scale wind farm and solar farm suitability assessment using GIS-assisted multi-criteria evaluation. Landscape and Urban Planning 138:20-31. DOI: 10.1016/j.landurbplan.2015.02.001.

World Wind Energy Association. 2018.Wind Power Capacity reaches 539 GW, 52,6 GW added in 2017. Available at https://wwindea.org/blog/2018/02/12/2017-statistics/ (accessed December 11, 2018).

Yaacobi G, Ziv Y, Rosenzweig ML. 2007. Habitat fragmentation may not matter to species diversity. Proceedings of the Royal Society B: Biological Sciences 274:2409-2412.

\section{Figure Captions}

Figure 1. Relationship between the proportion of developed land before the construction of a wind facility and the change in the proportion of undeveloped land before versus after construction. Points show each facility; the line shows the fitted line from a model-averaged beta regression holding other predictor variables at their mean value. Gray shaded area represents the $2.5 \%$ and $97.5 \%$ quantiles from 5000 bootstrapped replicates.

Figure 2. Relationship between the change in the core area index of undeveloped land before versus after construction and the proportion of developed land before the construction of a wind facility (a), the density of roads before construction (b), and the density of new roads (c). Points show each facility; the line shows the fitted linear relationship and 95\% confidence interval (gray shaded area) from the model-averaged-model holding other predictor variables at their mean value.

Peer] reviewing PDF | (2018:12:33453:2:0:NEW 10 May 2019) 
737 Figure 3. Relationship between the proportional change in the connectance index of undeveloped 738 land before versus after construction and the proportion of developed land before construction 739 (a), the density of new roads (b), and average slope (c). Points show each facility; the line shows 740 the fitted line from a model-averaged beta regression holding other predictor variables at their 741 mean value. Gray shaded area represents the $2.5 \%$ and $97.5 \%$ quantiles from 5000 bootstrapped 742 replicates.

743

744 Figure 4. Relationship between the proportion of developed land before the construction of a 745 wind facility and the proportion of the facility built on land that was developed prior to 746 construction. Points show each facility; the line shows the fitted relationship.

747

748 Figure 5. Relationship between the density of new roads after construction and the proportion of 749 developed land before the construction of a wind facility (a), the number of turbines (b), the 750 mean nearest neighbor distance between turbines (c), and the coefficient of variation in elevation 751 (d). Points show each facility; the line shows the fitted linear relationship and confidence interval 752 (gray shaded area) from the full model holding other predictor variables at their mean value.
753

754

755

756

757

758

759 


\section{Table $\mathbf{1}$ (on next page)}

Variable importance and parameter estimates for the statistical models

Relative Variable Importance using AICC (RVI), model-averaged standardized parameter estimates (MA standarized estimate), and their standard errors (MA standarized SE), the model-averaged parameter estimate (MA estimate) and their standard errors (MA SE) for explanatory variables used in each of the statistical models. Coefficient of variation in elevation (CV Elev), Average slope across facility extent (Slope), Nameplate capacity of turbines (Turbine size), nearest-neighbor distance (NN distance), density of new roads (New roads), proportion of developed land pre-construction (Pre-development), road density preconstruction (Pre-roads). 
Model and

variables

Change in the

proportion of

undeveloped land

Pre-development

Turbine Size

New Roads

Pre-roads

Slope

CV elevation

No. of Turbines

NN Distance

Change CAI at

$50 \mathrm{~m}$

Pre-development

New Roads

Pre-roads

No. of Turbines

Slope

Turbine size

$\mathrm{CV}$ elevation

NN Distance

Change in

Connectance

Index

New Roads

Slope

NN Distance

No. of Turbines

Pre-roads

Turbine Size

$\mathrm{CV}$ elevation
RVI

MA standardized estimate
MA

standardized

SE
MA

estimate

$\begin{array}{ccccc}1 & -0.4615 & 0.05154 & -1.2299 & 0.1374 \\ 0.5239 & 0.0435 & 0.0493 & 0.113 & 0.0486 \\ 0.4629 & 0.038 & 0.0483 & 0.0344 & 0.0158 \\ 0.3851 & -0.0267 & 0.0404 & -0.0081 & 0.0042 \\ 0.1464 & 0.0075 & 0.0229 & 0.0122 & 0.0088 \\ 0.1063 & -0.0041 & 0.0178 & -0.0033 & 0.0034 \\ 0.0680 & 0.0008 & 0.0105 & 0.0003 & 0.0011 \\ 0.0521 & 0.0017 & 0.0136 & 0.0003 & 0.0004\end{array}$

MA SE

0.0004 
New Road

Density

$\begin{array}{lccccc}\text { Pre-development } & 0.7021 & -0.580 & 0.5048 & -2.2028 & 1.0644 \\ \text { No. of Turbines } & 0.5819 & 0.5658 & 0.5692 & 0.0283 & 0.0117 \\ \text { CV elevation } & 0.3576 & 0.1823 & 0.3335 & 0.0431 & 0.032 \\ \text { NN Distance } & 0.3134 & -0.2861 & 0.4808 & -0.0081 & 0.0036 \\ \text { Slope } & 0.1542 & 0.0091 & 0.1758 & 0.0141 & 0.1063 \\ \text { Pre-roads } & 0.15 & -0.019 & 0.1528 & -0.0148 & 0.044 \\ \text { Turbine Size } & 0.1130 & 0.0291 & 0.1462 & 0.3471 & 0.4878\end{array}$


Figure $\mathbf{1}$ (on next page)

Relationship between the proportion of developed land before the construction of a wind facility and the change in the proportion of undeveloped land before versus after construction.

Points show each facility; the line shows the fitted line from a model-averaged beta regression holding other predictor variables at their mean value. Gray shaded area represents the $2.5 \%$ and $97.5 \%$ quantiles from 5000 boot-strapped replicates. 


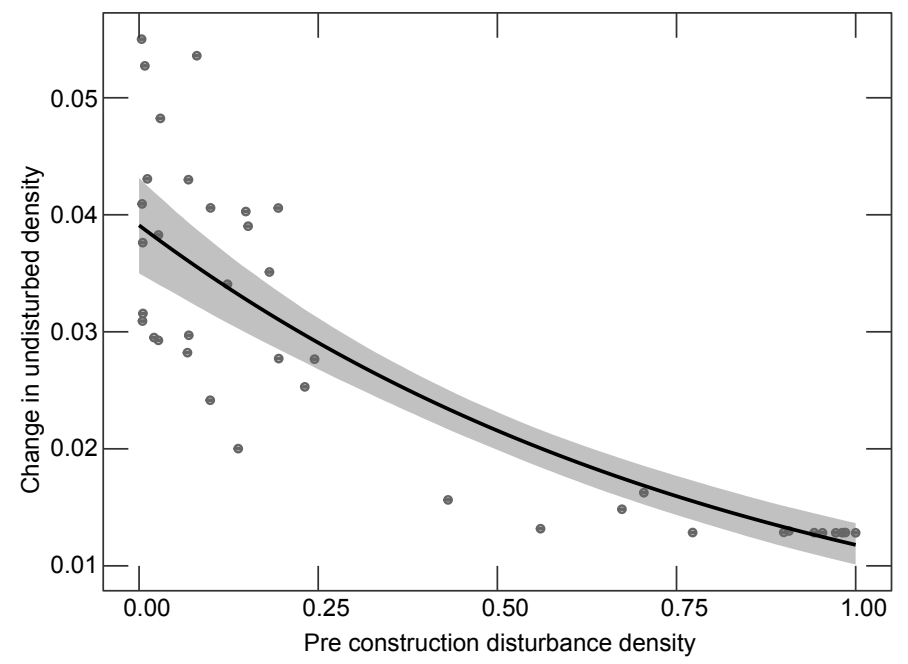


Figure 2 (on next page)

Relationship between the change in the core area index of undeveloped land before versus after construction and three explanatory variables.

Points show each facility; the line shows the fitted linear relationship and $95 \%$ confidence interval (gray shaded area) from the model-averaged-model holding other predictor variables at their mean value. (A) The proportion of developed land before the construction of a wind facility, (B) The density of roads before construction. (C) The density of new roads. 
a.

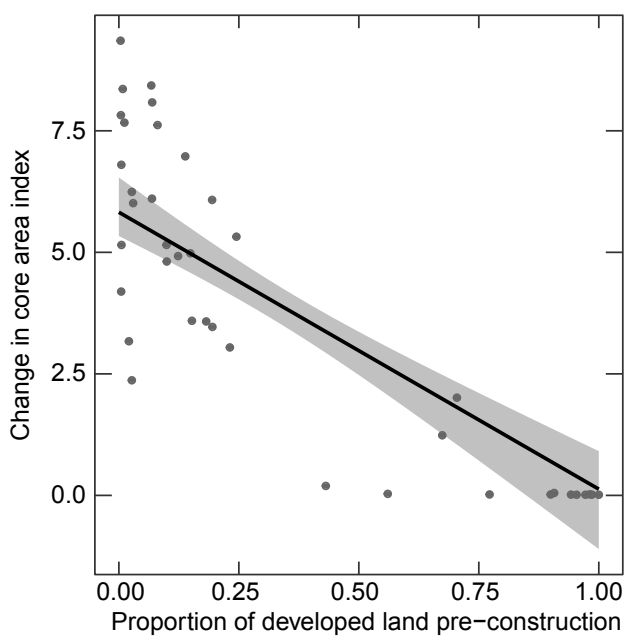

b.

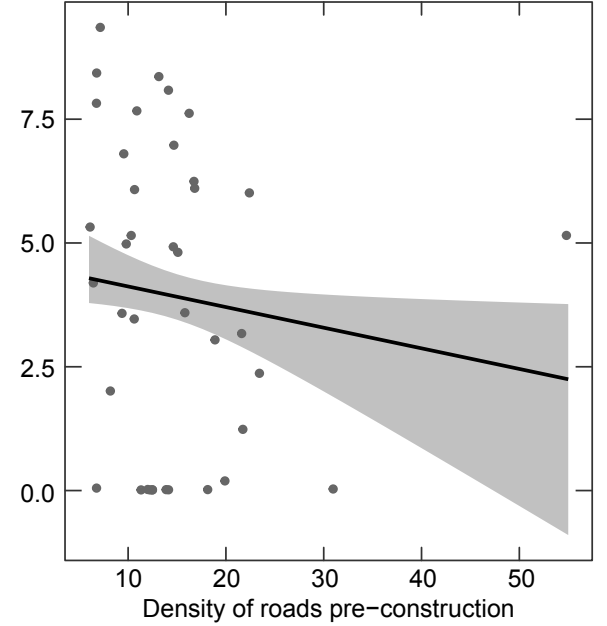

c.

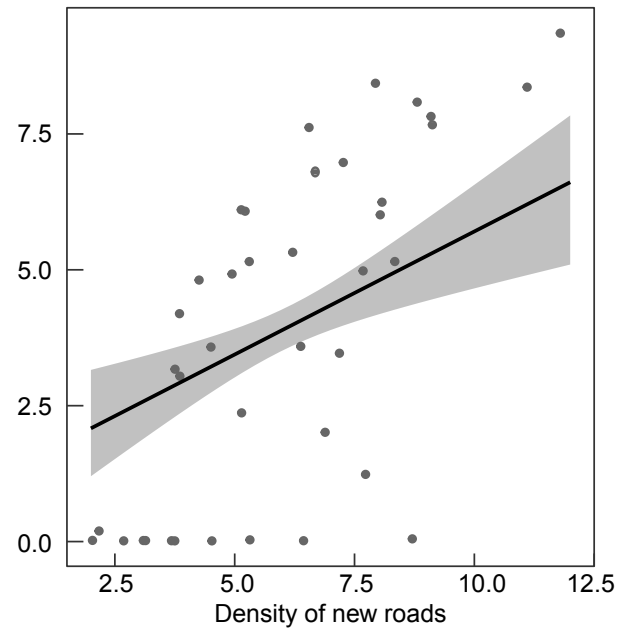


Figure 3 (on next page)

Relationship between the proportional change in the connectance index of undeveloped land before versus after construction and three explanatory variables.

Points show each facility; the line shows the fitted line from a model-averaged beta regression holding other predictor variables at their mean value. Gray shaded area represents the $2.5 \%$ and $97.5 \%$ quantiles from 5000 boot-strapped replicates. (A) The proportion of developed land before construction. (B) The density of new roads. (C) Average slope. 
a.

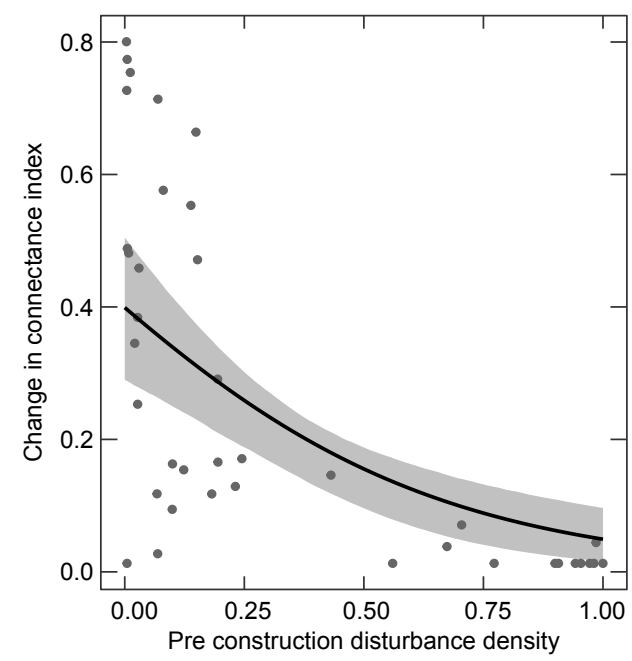

b.

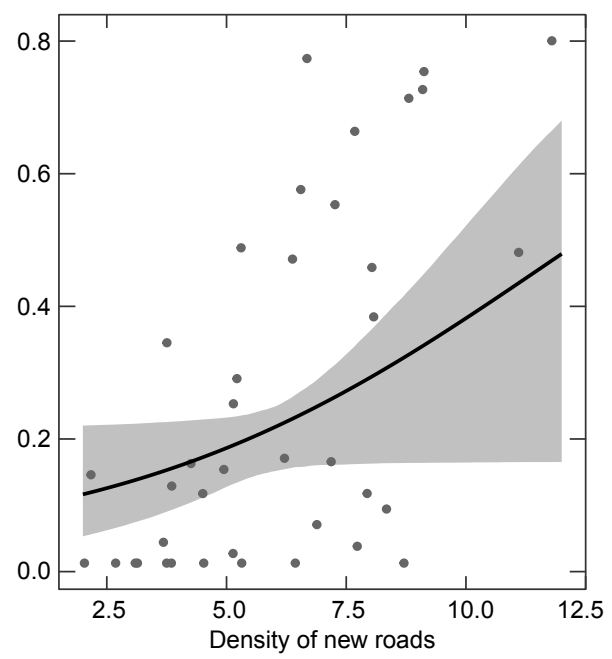

c.




Figure 4 (on next page)

Relationship between the proportion of developed land before the construction of a wind facility and the proportion of the facility built on land that was developed prior to construction.

Points show each facility; the line shows the fitted relationship. 


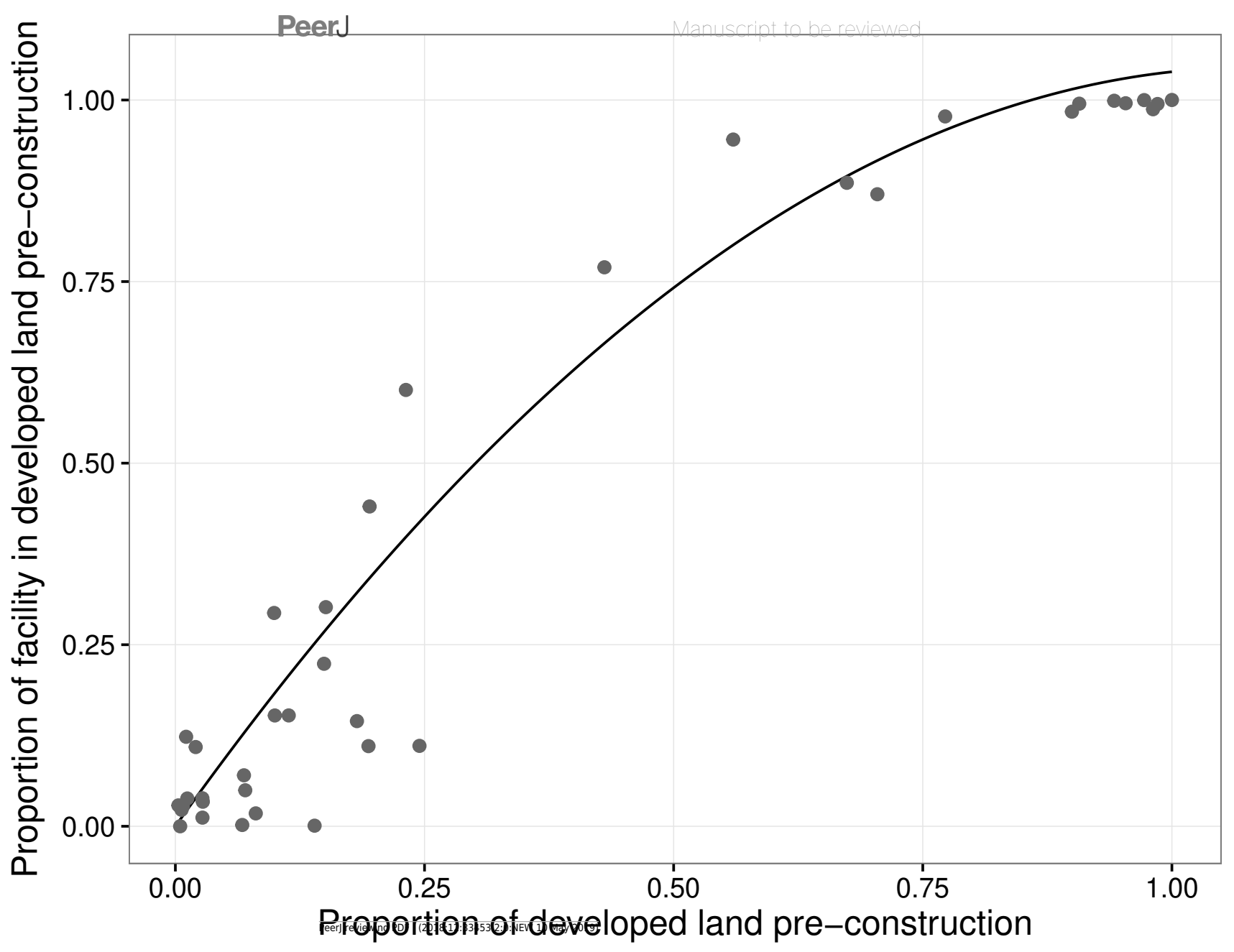


Figure 5 (on next page)

Relationship between the density of new roads after construction and the proportion of developed land before the construction of a wind facility and 4 explanatory variables.

Points show each facility; the line shows the fitted linear relationship and confidence interval (gray shaded area) from the full model holding other predictor variables at their mean value. (A) The proportion of developed land before the construction of a wind facility. (B) The number of turbines. (C) the mean nearest neighbor distance between turbines. (D) The coefficient of variation in elevation. 
a.

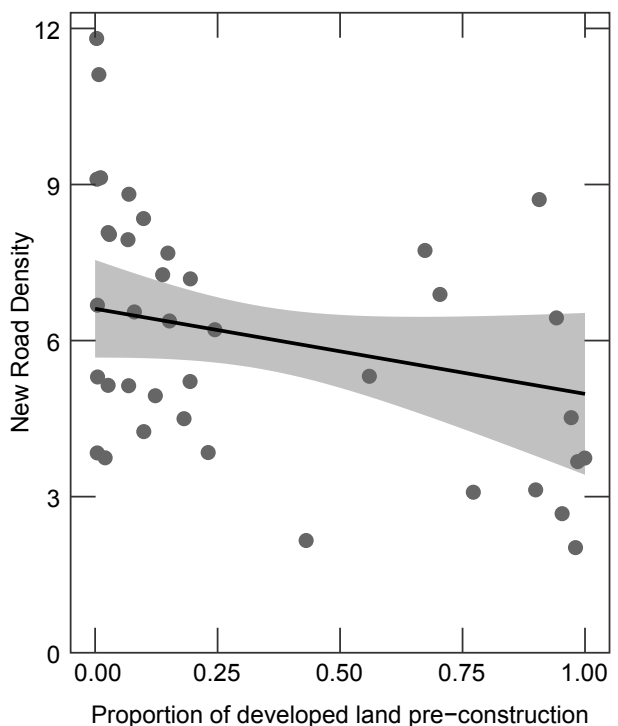

c.

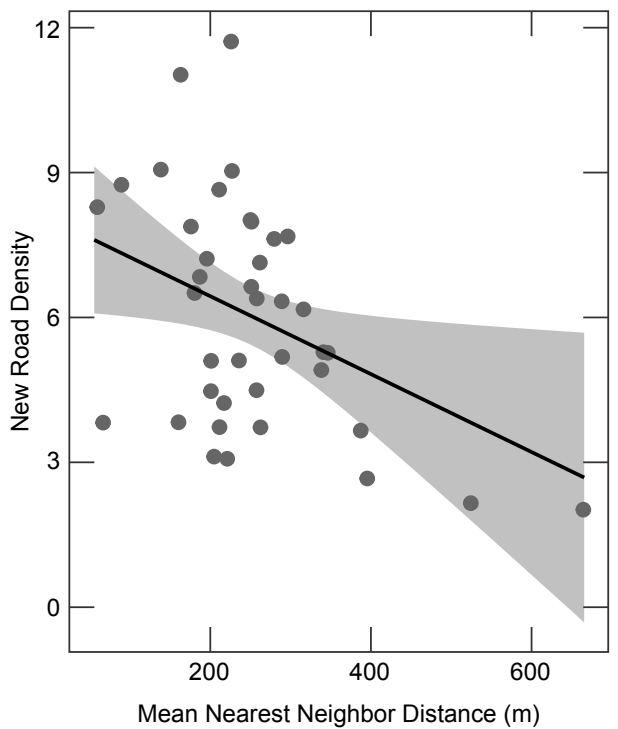

b.

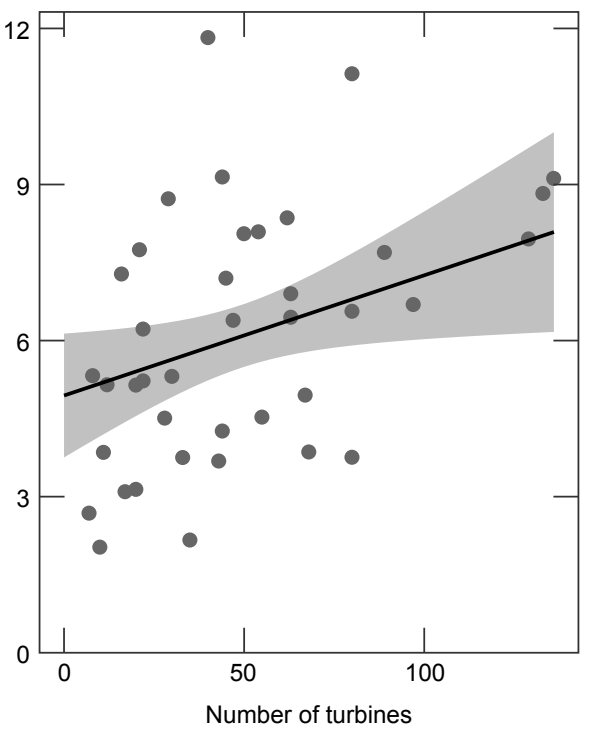

d.

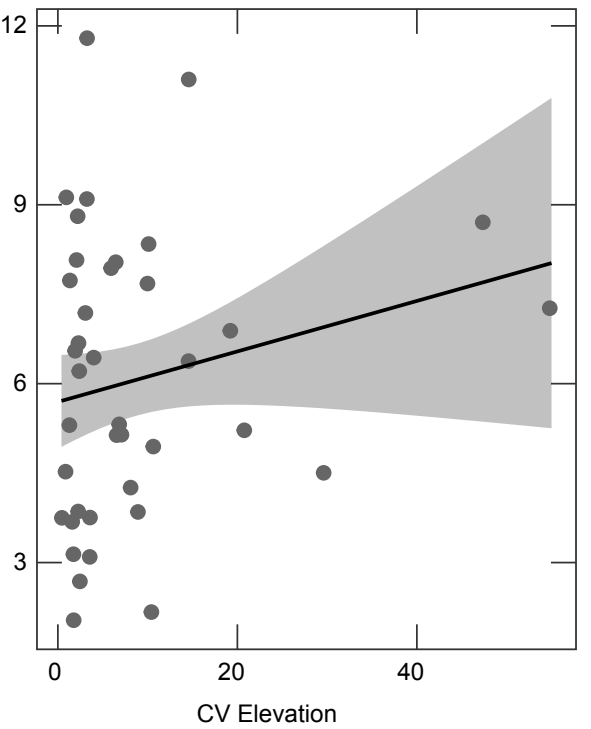

